\title{
Considerations on the phylogeny of the axial skeleton
}

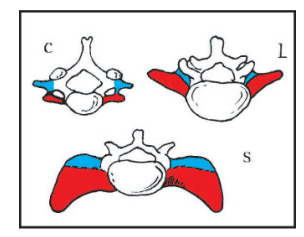

\section{R. FENART}

with the collaboration of Jean-Marie LANDOUZY

and Dr Anne Sergent Delattre

\begin{abstract}
This article reviews the main trends in the evolution of the vertebrate axial skeleton, with special focus on mammals. The structure of vertebrae is exposed according to traditional and current conceptions and several examples of species-specific and topography-specific adaptations are given. The relationships between stature and the anatomy of the bony girdles surrounding the spine are discussed. Hypotheses on the influence of gravity on axial morphogenesis are formulated.
\end{abstract}

\section{KEYWORDS}

Vertebra

Spine

Phylogenesis

Standing position

Pelvis

Nape. 
In Invertebrates, the forces exerted by muscles are transmitted to an "external skeleton», such as the calcified plates of the sea urchin (an Echinoderm) or the chitineus covering of many Arthropods (including Insects). This external skeleton can be internalized, as for instance in Cephalopod Mollusks such as the cuttlefish.

In some more derived animals without vertebrae, a "chord" acts as a median, axial, tonic and elastic structure. The first occurrence of the chord takes place in Enteropneusta Balanoglossus. The Balanoglossus is a Stomochordata and his chord is reduced to a nodule located behind the mouth, dorsally. In Ascidians (Urochordates), a chord is found caudally at the larval stage. The chord of Ascidians does not persist in adult stages. Ascidians are also know as "sea skirts", "violets" or "bajus" (in Marseilles).

Cephalochordates, represented by the Amphioxus (fig. 1), are believed to be the most derived Invertebrates. The chord of Cephalochordates extends on the whole length of their body and persists in adults stages. From an evolutionary point of view, chord apparition is contemporary to the progressive migration of the central nervous system from a ventral position (double chain) to a dorsal position (neural tube). The chord is located on the ventral side of the neural tube and on the dorsal side of the aorta. The aorta itself is situated on the dorsal side of the digestive tract (fig. 2). These basic anatomical principles are useful to understand the evolution of Vertebrates.

In Vertebrates, there is a progressive regression of the chord, which is

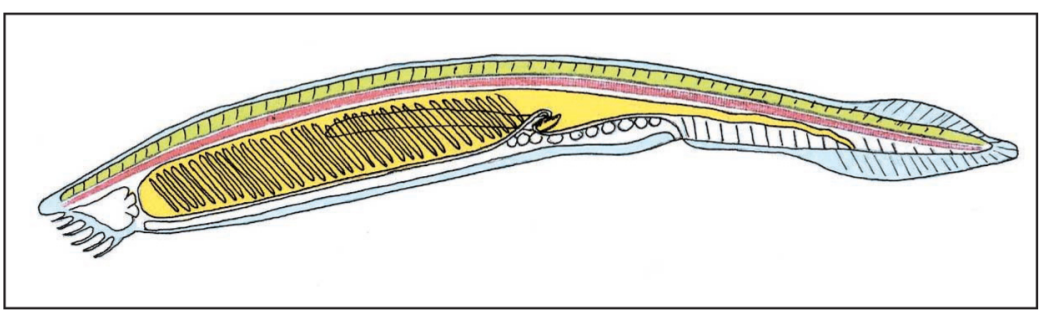

Figure 1

Amphioxus.

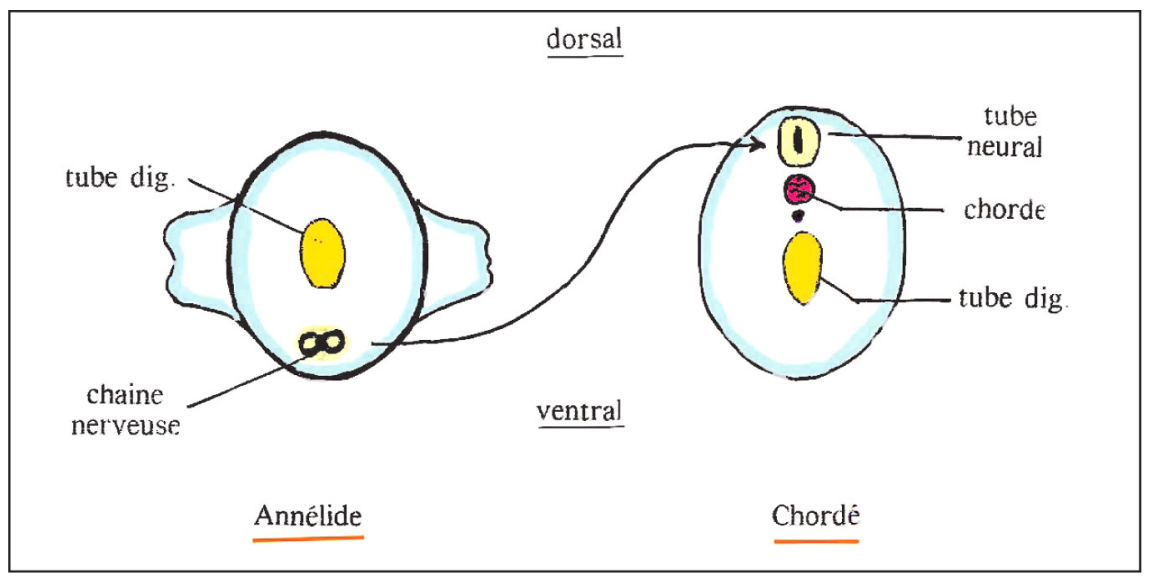

Figure 2

Dorsal drift of the nervous system axis, from invertebrates to chordates (and vertebratess). 


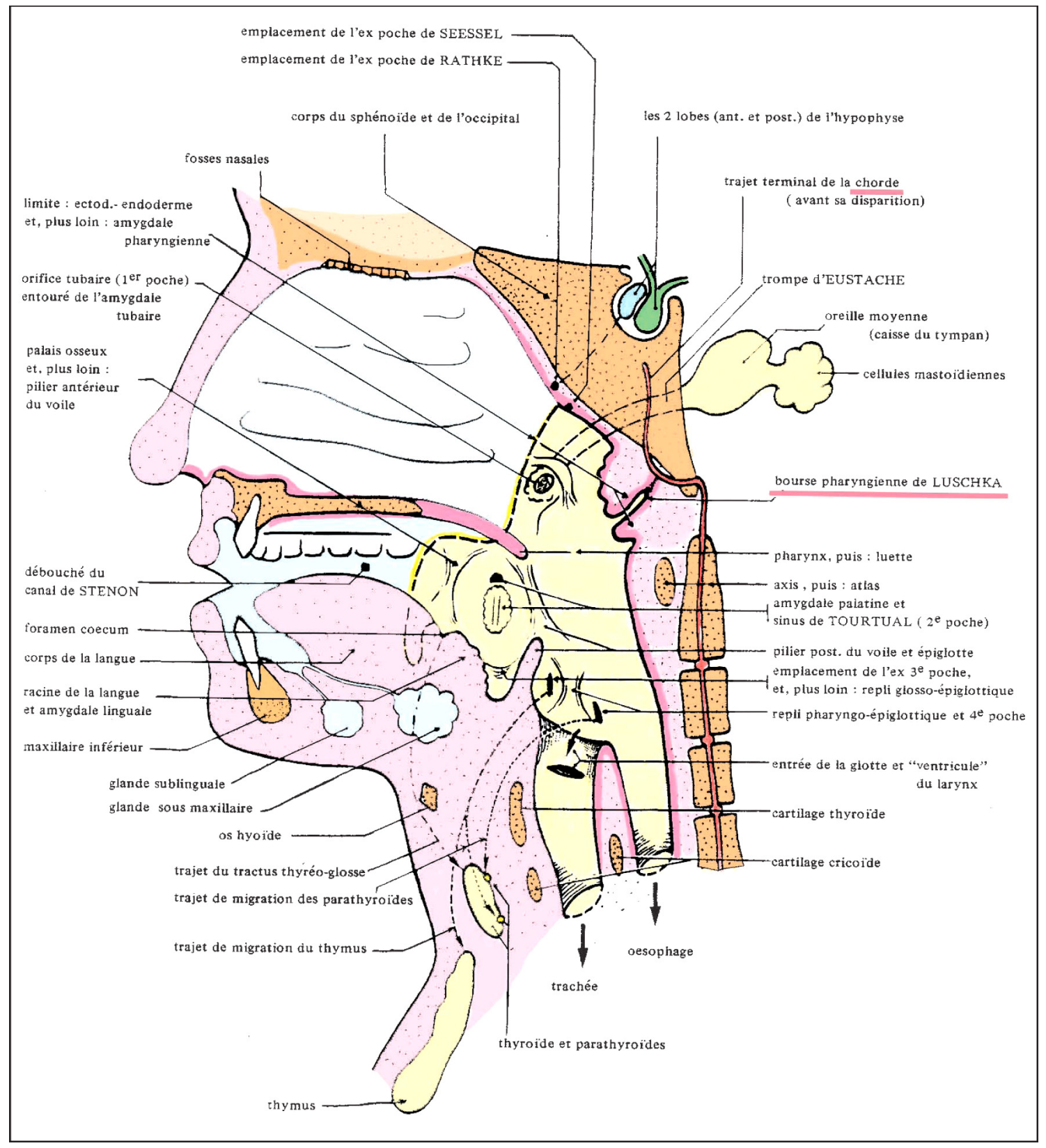

Figure 3

Pathway followed by the chord in the cervico-occipital joint.

gradually replaced by discrete structures that will finally form vertebrae by fusion and constitute the skeletal axis of the body. The elements involved in this progressive transformation are: possibly the chordal cells but more importantly the perichordal sheath and skeletal - bony or cartilaginous - structures known as "arculiae". Arcualiae are located around the chord. Interestingly, 
it is known today that cartilage is not a primitive condition that gave rise to bone but can in some cases be the result of a bone de-differentiation.

In all Vertebrate species, the chord extends on the whole length of the spine. Its anterior, cranial, limit is the hypophysis. In Human embryos, the chord travels dorsally to the basion of the foramen magnum and exits immediately under the "basilar" section of the basi-occipital; the chord then extends dorsally and ends in the body of the sphenoid, in a caudal position compared to the sella turcica (figure 3). This complex pathway is explained by embryology and is the consequence of an early fusion between chordal tissue and endoderm, in what will become the "Luschka pouch" of the pharyngeal tonsil (the pharyngeal adenoid). The presence of chordal tissue in the posterior part of the embryonic skull is not surprising as this region results from the fusion of vertebral elements (according to the observations of Jarvik $^{6}$ on fossil Crossopterygians).

A vertebra is formed by a "vertebral body" and by arcualiae derivatives on which the diverse processes are connected.

\section{- The vertebral body}

Vertebrates display several types of vertebral bodies, according to their embryonic origin and their fate.

- Acentric vertebra. The acentric v. is deprived of vertebral body (and thus of skeletal tissue) and is only composed of the chord and of chordal sheaths. The arcualiae are adjacent to this vertebra and bear the neural and hemal "arches". This simple pattern is found for instance in Chondrostean Fish such as the Sturgeon.

- Chordacentric vertebra. The chord is reduced and takes part in the formation of the vertebral body ("chordacenter" of the body) by ossification. Ossified peri-chordal sheaths are also integrated in the $\mathrm{v}$. body and are known as the "autocenter". This structure is surrounded by the skeletal elements bearing the arches. This pattern is found in Selachian Fish such as Sharks.

- Arcocentric vertebra. The vertebral body essentially derived from arcualiae ossification. The participation of the chord and perichordal sheaths in this process is poorly known. In adults, the highly regressed chord persists in the center of intervertebral discs and is known as the nucleus pluposus (source of discal hernias!). All Amniotes follow this vertebral formation pattern, including Man.

\section{- Body segmentation and the theory of Gadow}

The theory formulated by Gadow ${ }^{4,5}$ has been used to establish a classification of arcocentric vertebrae. This theory is still widely admitted event though it is highly criticized by embryologists and histologists. In fact, the cellular agglomerates mentioned by Gadow are not easily visible during development.

During the first stages of their development, vertebrae - mainly truncular vertebrae - are metameric, which means that their structure - the "metamere" - is regularly repeated along the body axis. An typical example of metameric structure is given by the "somites". Somites are located in the mesoblast, and more precisely in the paraxial mesoblast, situated on both sides of the chord. The internal part of each somite is called the "sclerotome" and gives birth to the arcualiae while its two other sub-parts 
(the "myotome" and the "dermatome") have other fates.

The Von Ebner ${ }^{14}$ groove separates each somite into two parts along their cranio-caudal axis. These subparts are known as "sclerosomites". Vertebrae arise from the fusion between the caudal sclerosomite (ca. s.) of one segment and the cranial sclerosomite (cr. s.) of the following segment. According to this mechanism, each vertebra overlaps two metameres and conversely, one metamere overlaps two vertebrae. The metameric sequence is thus said to alternate with the vertebral sequence.

Gadow $^{4,5}$ hypothesizes that the ca. $\mathrm{s}$. is formed by the arcualiae bearing the neural and hemal arches, surrounding respectively the neural tube and the aorta. These arches form the two basi-dorsals (BD) and the two basi-ventrals (BV). The cr. s. bears two inter-dorsals (ID) and two inter-ventrals (IV) but no arches. An arcocentric vertebral body is thus composed of eight fundamental elements organized in two rings.

This theoretical scheme presents many variations depending on the species, the environmental characteristics and the localization of the vertebra along the cranio-caudal axis.

In cases where the vertebral body keeps its "doubled" aspect, the vertebra is called dispondyle or embolomere (figure $5 \mathrm{~d}$ ). Such pattern is found in certain Fish.

When the eight original anatomical subparts of the ancestral vertebra fuse to form three skeletal masses, the vertebra is known as rachitome (figure $5 r$ ), with a well developed pleurocenter (p) arising from the fusion of the IVs, a smaller hypocenter (h) or inter-center obtained by the fusion of the BVs and a BD group sustaining the neural arch. The ID regress. The rachitome vertebrae are found in Theromorph Reptiles (extinct Mammalian ancestors).

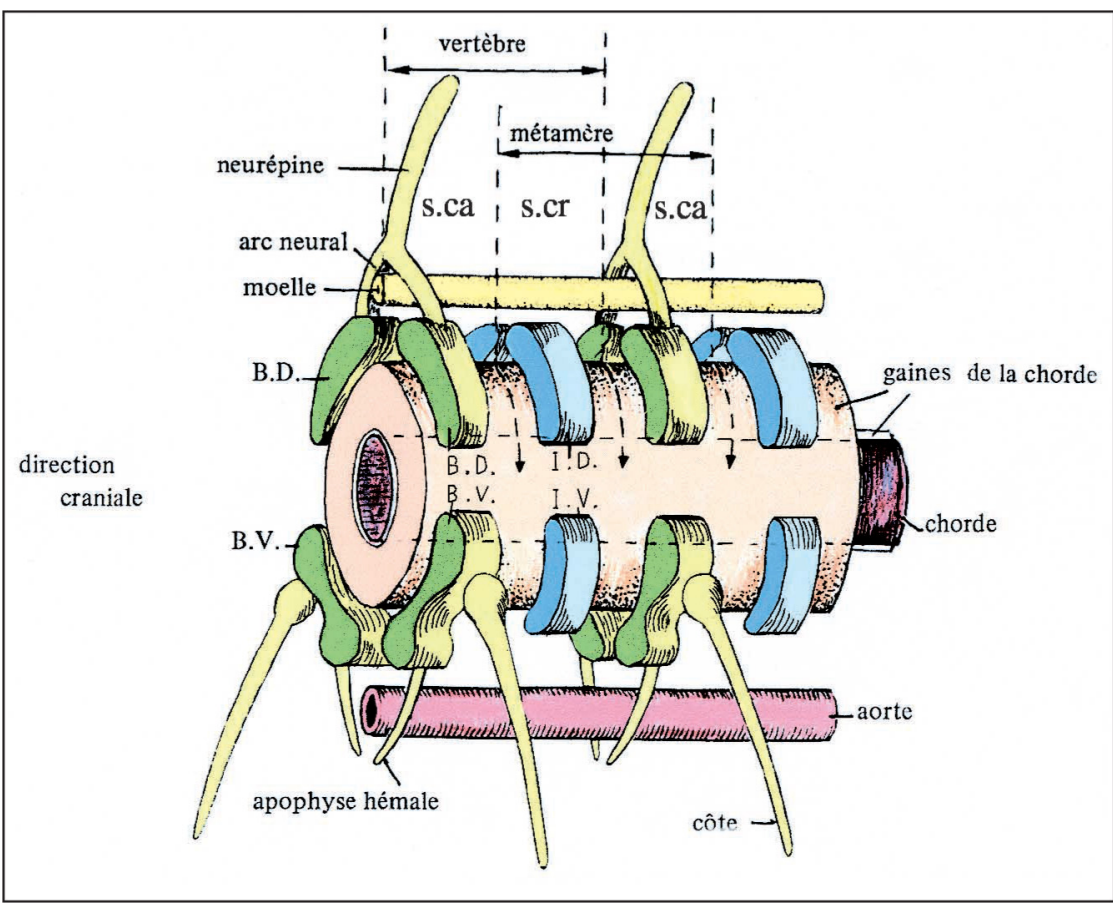

Figure 4

Gadow theory: typical vertebra, defined by the localization of the arcualiae.

BD: basi-dorsal;

$B V$ : basi-ventral;

ID: inter-dorsal;

IV: inter-ventral;

cr.s.: cranial sclerotomite;

ca.s.: caudal sclerotomite. 


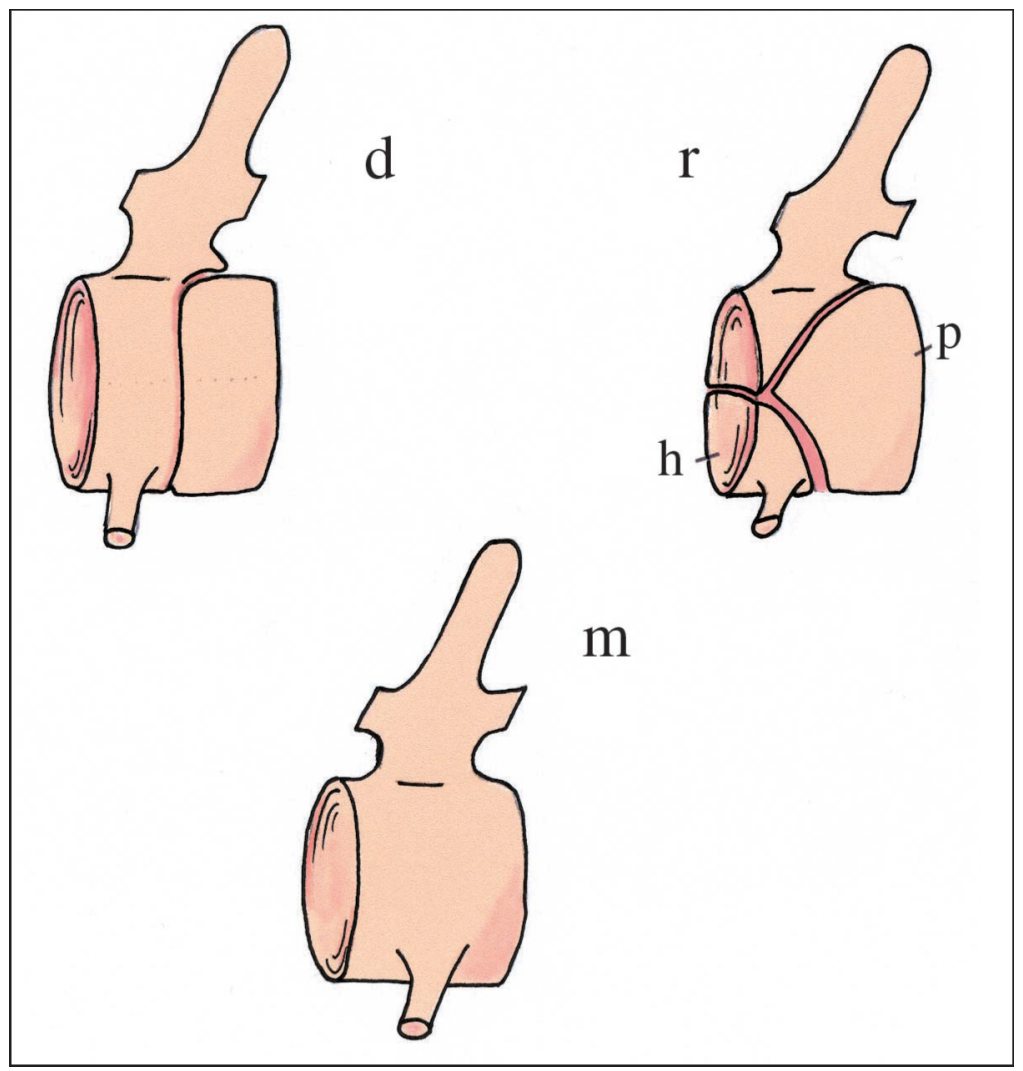

Figure 5

Vertebral schematization: diplospondyle $(d)$, rachitome $(r)$, monospondyle $(m)$.

An equivalent of rachitome vertebra with partial ossification is also found in Eusthenopteron, a Crossopterygian Fish considered by some authors as an ancestor of most of the extant vertebrates.

Stereospondylia is another pattern of vertebral organization. In this case, the vertebral body is composed of the BVs - the IVs have regressed. Stererospondylia is found in Urodele Amphibians and will not be considered further in this paper.

When all the sub-parts described in the ancestral vertebra persist and fuse together, the vertebra is called monospondyle or haplospondyle (figure $5 \mathrm{~m}$ ). Mammals have such vertebrae.

Remark: all vertebrae except monospondyles are called lem- nospondyles; their vertebral body always exhibits a certain degree of fragmentation.

In Humans, vertebrae are monospondyle (figure 6). The equivalences between the eight arcuale elements of Gadow ${ }^{4,5}$, the three sub-parts of the rachitome vertebra and the usual human anatomical terminology are given further.

- The inter-dorsals have totally regressed.

- The main components of the vertebral body are the inter-ventrals, called the "pleurocentre". Human vertebra are also referred to as "gastrocentric" ! Chordal tissues (chordacenter) and peri-chordal elements almost certainly contribute to the formation of the vertebral body. 


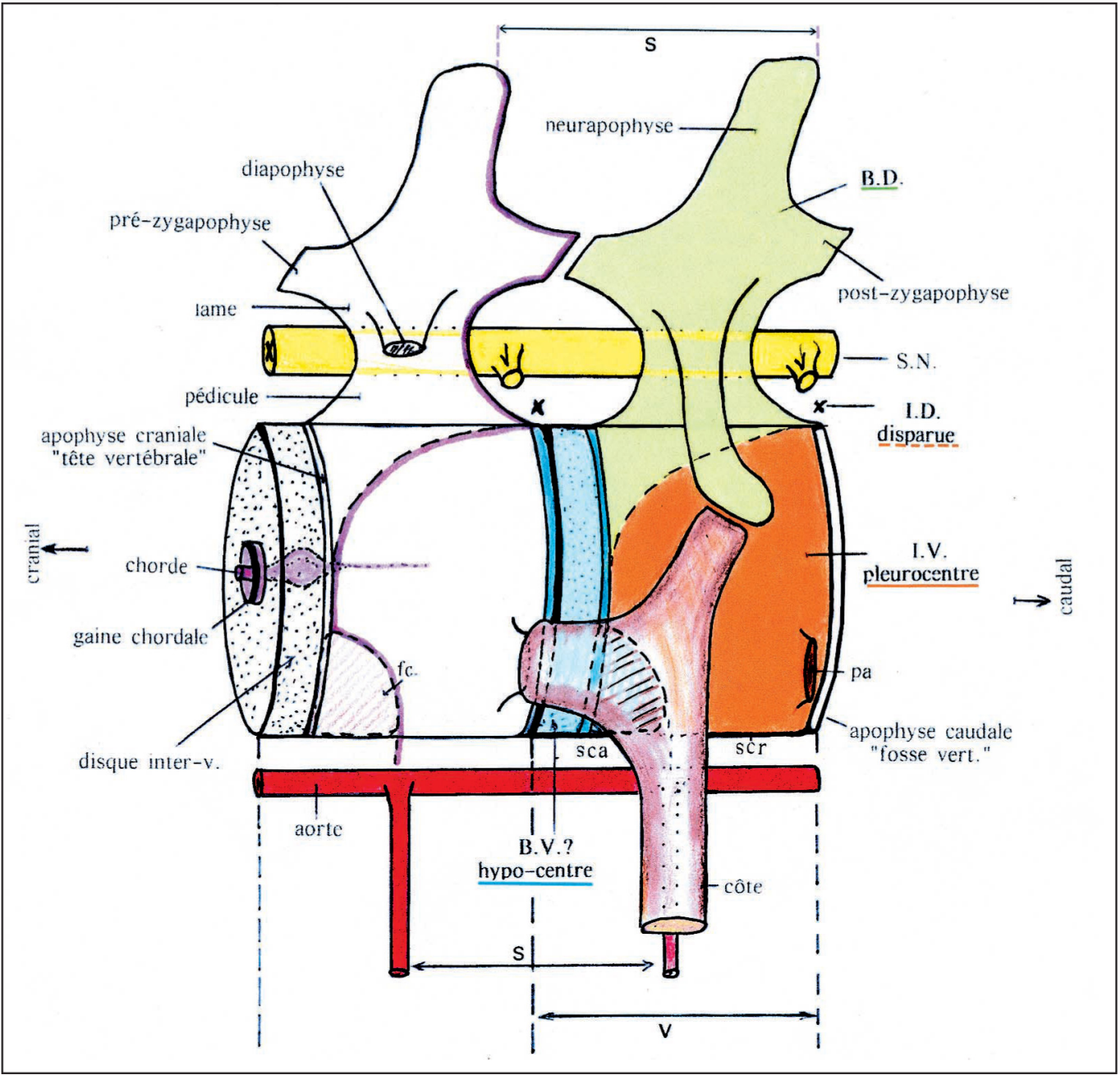

Figure 6

Correspondence between mammalian vertebrae, sclerotomites (ca.s and cr.s) and arcualiae; fc: fovea costalis; pa: parapophysis.

- The basi-dorsal form the neural arch and its processes. This structure progressively drifts backwards and finally localizes itself over the pleurocenter.

- The basi-ventrals barely contribute to the formation of the human vertebrae. The are at the origin of the "hypocenter". The hemal arch regresses, except in the caudal region of kangaroos, where it takes the form of herringbones "Y-bones".
It is furthermore generally admitted that the inter-vertebral discs, the cranial process ("vertebral head") and the caudal process ("vertebral groove") derive from the BVs.

These processes form as individualized boards arising from independent ossification centers and secondarily fuse to the anterior and posterior parts of the vertebral body (figure 6). 


\section{- Processes (fig. 6)}

The neural arch arises from the dorsal BD on the dorsal part of the neural tube. This arch is connected to the vertebral body by processes and laminae. The terminal process of the arch is called the processus spinosus (neurapophysis). Laterally, the arch bears the transverse processes (diaposhyses) and the cranial and caudal articular processes (resp. pre- and post-zygapopyses). Other extensions are described: metapophyses (or mamillay processes), anapophyses (or styloid processes), parapophyses (see definition in the paragraph on ribs), pleurapophyses (fusion between diapophyses and coastal relics, in a non-thoracic localization) (figure 7).

\section{- Occipito-vertebral joint}

The cephalic end of the body includes, added to the five segments of the paleocranium, three neocranial segments formed by the addition of truncal metameres. According to the resegmentation principle, there is an excess of half a vertebra on the occipital side of the spine. In fact, the most cranial vertebra divides into two sclerotomites, one fusing with the occipital bone and the other, the pro-atlas, which can adopt diverse developmental patterns. When the pro-atlas fuses with the occipital bone, several structures can appear, such as a "third condyle", an isolated ossiculum between the occipital basion and the dens or, more frequently, a surnumerary bone fused with the dens tip. The dens is thus formed by the body of the axis, the body of the atlas and the pro-atlas.

Cranial nerve anatomy parallels the segmented structure of the craniocervical joint. In fact, (1) the three roots of the hypoglossal nerve XII cor-

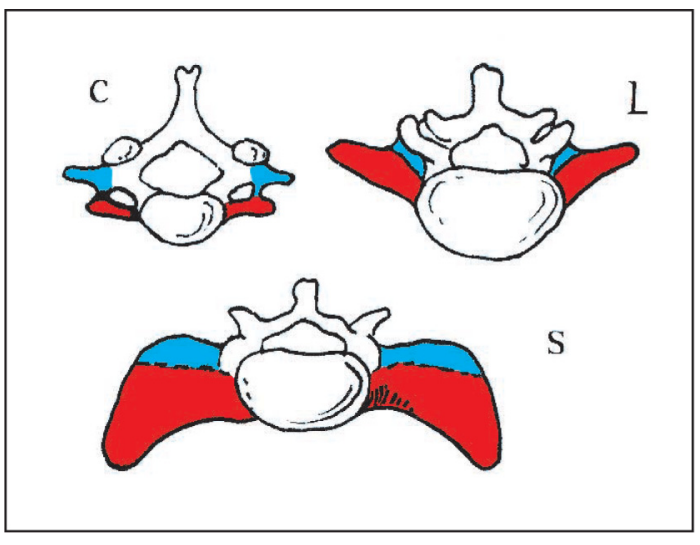

Figure 7

C: cervical vertebra; L: lumbar vertebra; $S$ : sacral vertebra; in red: costal remnants; in blue: transversal processes.

respond to each one of the neocranial segments, (2) the first cervical nerve C1 corresponds to the proatlas and to the caudal sclerotomite of the first segment from which derives the anterior part of the first vertebra (atlas), (3) the second cervical nerve C2 corresponds to the second segments, etc.

Interestingly, C1 has a limited physiological role as its sensory fibres are lost (as in the hypoglossal nerve). In fact, the occipital nerve of Arnold is a branch of the second cervical nerve C2.

The cranio-cervical joint of Fish is formed by direct contact of cranial and spinal median surfaces. In Amphibians, two lateral facets and a median tubercle are found. High mobility is a property of the Amniote epistrophean joint, which permits a full rotation of the skull on the spine.

The cranio-occipital joint derives from a "primitive condyle" formed by three subparts extending on the basioccipital and the exo-occipital (laterally). Schematically, most Reptiles and Birds have one condyle, some Reptiles 


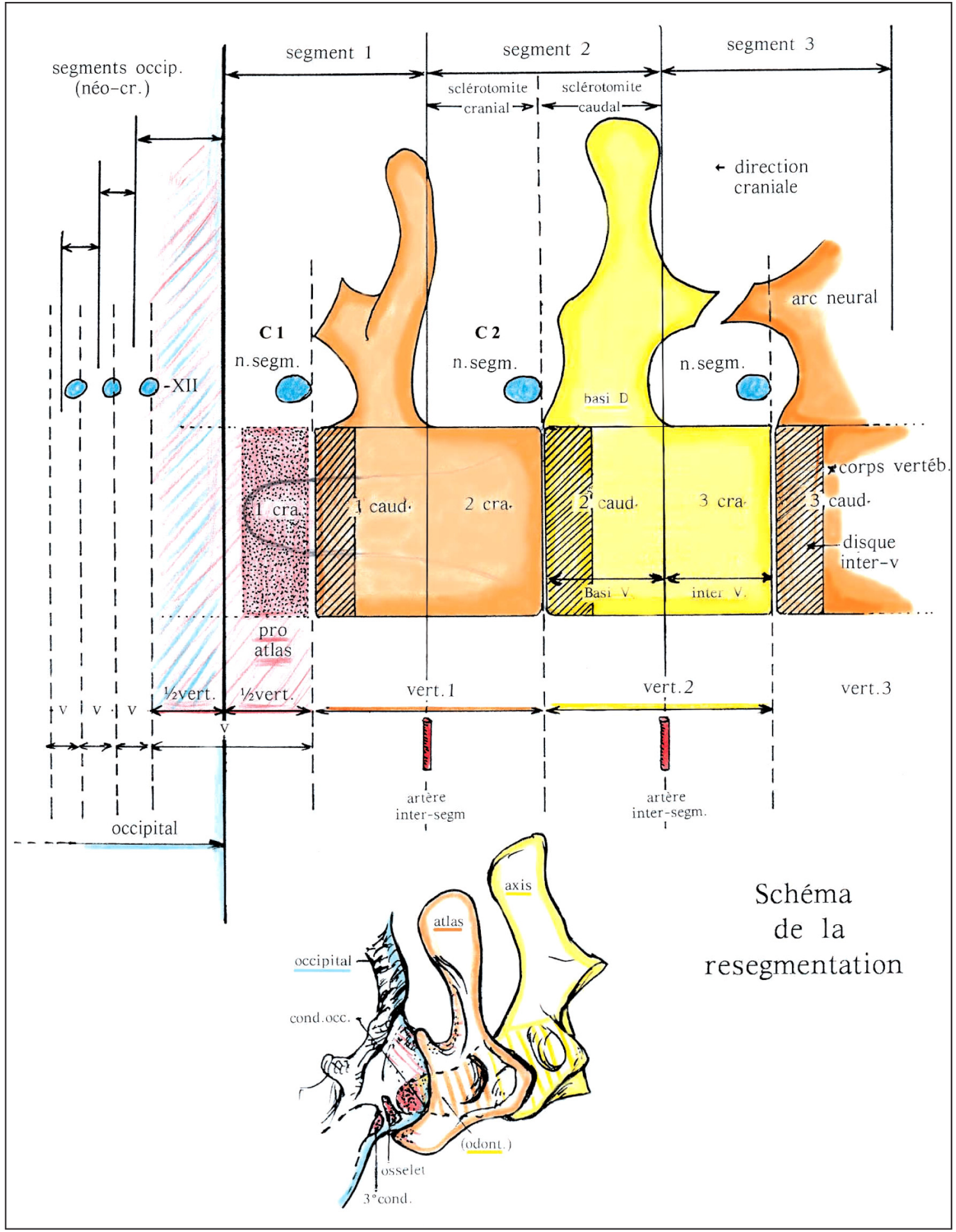

Figure 8

Cervico-occipital joint; upper part: theoretical distribution of vertebral segments; lower part: real aspect. 
have three condyles and Mammals two.

\section{- Cranio-costal relationships}

The developmental pathways that lead to the formation of ribs don't overlap with the ones leading to the formation of vertebrae. The costo-vertebral joints form secondarily. Furthermore, ribs cannot be identified to hemal arches.

Two categories of ribs are classically described: (1) "inferior" ribs and (2) "superior" ribs (that is, more dorsally situated). The latter do not exist among Mammals. The "inferior" ribs, or ribs s.s., are in proximity with the caudal sclerotomite (BV) via a capitulum, forming a joint on the side of the vertebra facing the rib, the "fovea costalis". The costal head also forms a joint with the cranial sclerotomite of the more anteriorly located vertebra via the "parapophyse" (figure 6). Another contact zone between the ribs and the vertebrae is the tuberculum of the transverse process. In the cervical, lumbar and sacral regions, vestigial ribs remain and fuse with the transverse processes, forming a dual structure called the pleurapophyse.

\section{- Vertebral shape}

The shape of vertebrae depends on their localization along the spinal axis: cervical, thoracic (or dorsal), lumbar, sacral and caudal. There is also a great variability from one species to another. The limits between the different anatomical regions of the spine are not always easy to establish.

Several morphological characteristics illustrate the importance of vertebral positional identity, such as the transformations leading to the formation of $\mathrm{C} 1$ and $\mathrm{C} 2$ in Mammals, the resemblance of C7 with thoracic vertebrae (no transversal foramen) and more interestingly, the peculiar shape of S1, called "fulcral" vertebra by Wlecker. When the "winglets" (pleurapophyses) of S1 are located more caudally than the cranial side of the sacrum, such as in Humans, the spine morphology is said to be "hypobasal" (figure 9). Hypobasality would be a consequence of the erected posture (Radlauer) ${ }^{11}$, as other Mammals are "hyperbasal", the winglets of S1 being in a more cranial situation. In the Human species, the cranial side of the fulcral vertebra has to support all the pressure of the upper parts of the body, that $1 \mathrm{~kg}$ per $0.22 \mathrm{~cm}^{2}$. This weight is transmitted to the pelvis via the articular side of S1 and further to the lower limbs via the coxo-femoral joint.

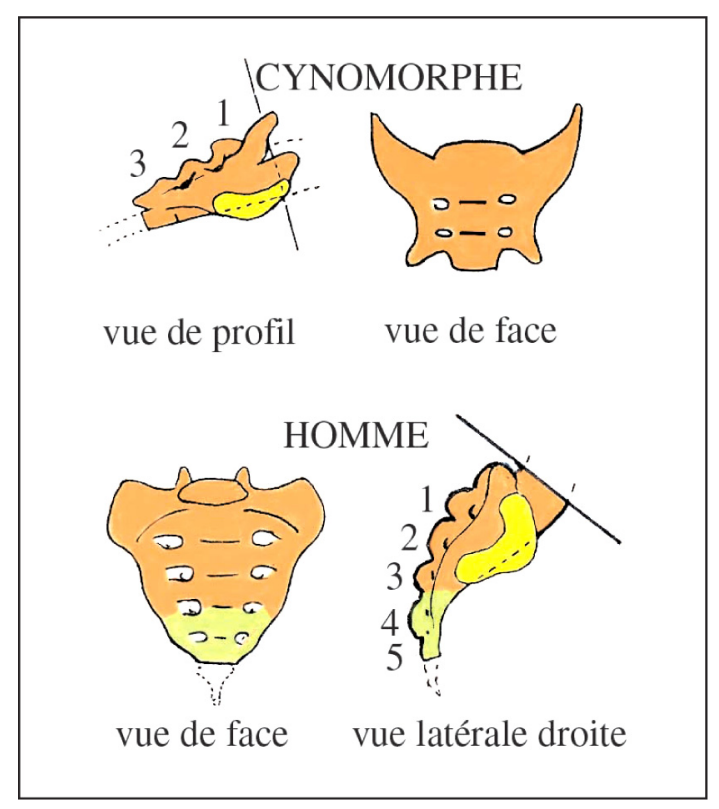

Figure 9

S4 and S5 addition to the primordial sacrum in humans. 


\section{- Structure}

According to Kummer ${ }^{8}$, the direction of the bone trabeculae is parallel to the tensile forces and perpendicular to pressure.

\section{- Vertebral formula}

The vertebral formula is highly variable, especially in the most caudal sections of the spine. The number of cervical vertebrae (7) is in fact almost always constant: Giraffes and Dolphins both have the same number of cervical vertebrae but they measure $35 \mathrm{~cm}$ in the former species and $1 \mathrm{~cm}$ in the latter.

The number of thoracic vertebrae varies between 10 (in the Armadillo) and 24 (in the Sloth). Manatees have 1 lumbar vertebra while Dolphins have 18 of them. Kangaroos only have 2 sacral vertebrae while armadillos have 9 of them. Finally, the caudal vertebrae can be as numerous as 34 (in the Whale) but also be reduced to four fused elements (in the Human coccyx). Furthermore, the $(7 \mathrm{C}, 12 \mathrm{~T}, 5 \mathrm{~L}$, $5 S$, 40) formula of humans is only valid in 2/3 of individuals and doesn't take into account for instance presacral vertebrae. The most numerically unstable region in human spine is the lumbo-sacral region. A common compensation by formula modifications in the regions surrounding the instability is observed.

From a phylogenetic point of view, the pre-sacral vertebrae regress from Theropsids to extant Mammals, as if the pelvis had traveled forwards towards the skull in a way called "spine cranialisation".

The Cynomorphs (such as the Macaque) and the Anthropomorphs (such as the Gorilla) have 13 thoracic vertebrae but Humans only have 12 .
Conversely, Humans have 5 lumbar vertebra, Gorillas only 4 and Cynomorphs 7. Gorillas have 6 sacral vertebrae and Humans only 5. It thus appears that in Anthropomorphs and Humans, the sum $L+S$ is constantly equal to 10 . According to Delmas ${ }^{3}$, the erected posture has led to the transfer of a sacral vertebra to the lumbar region, but this theory is highly disputed.

The primordial sacrum occurs in Mammals up to Cynodonts (3 fused vertebrae laterally jointing with the iliac bones). Anthropomorphs have two surnumerary sacrum vertebrae and an narrow and long sacrum while Humans have three extra vertebrae, located caudally in a broader sacrum. These vertebrae are known as "pseudosacral" vertebrae (figure 9) and don't occur in primates with non-erected standing position. In Humans, they keep the attachments of the sturdy perineal muscles and ligaments which hold the visceral organs, located above and no more in front of the pelvis.

\section{- Segmental length}

The length of each vertebral segment compared to the total pre-sacral length of the spine shows that the human lumbar region is relatively the widest. According to Keith7, this phenomenon is probably related to the erected position.

\section{- Vertebral weight}

Pineau and Delmas ${ }^{9,10}$ have compared the weight of each vertebra to the weight of the whole column. The curve giving the relative weight of each vertebra according to its localization along the axis has two maxima in quadrupeds (T1 and L1) but is constantly growing caudal wards in Humans. Inertia curves have been 
established by Slijper ${ }^{12}$, knowing that $w=b \cdot h^{2} / 6$, with $b$ and $h$ being resp. the transversal and longitudinal diameters of the vertebral body. Slijper obtains the same conclusions as Pineau \& Delmas. Both authors deduce that the vertebral mass is related to the lifestyle of the subject. A first mechanical system occurs in quadrupeds and mainly involves the relationships of the head with the scapular girdle. The mechanical system of bipeds on the other side relies on the pelvic girdle as the weight of the subject is directed towards its caudal extremity.

\section{- Straightening up of the body}

The modification of the general direction of the body axis induces a movement of the center of gravity, which is located at the level of T5 in quadrupeds, of T12 in Cynomorphs, of L1 in Anthropomorphs and L3 in Humans. The polygon of support is strongly reduced in bipeds and the Human vertical axis joins the labyrinth of the inner ear, L3, the sacro-lumbar angle, the femoral head and the feet (figures 10, 11).

The sacrum doesn't follow the same pattern of verticalisation as the rest of the spine: a sacro-lumbar angle with dorsal opening persists. This angle attains $115^{\circ}$ in Humans, $150^{\circ}$ in Anthropomorphs and $170^{\circ}$ in Cynomorphs. The sacral movements induce the displacement and verticalisation of the genital organs.

The classical consequences of erection are well known, such as for example the "freedom of hands". Interestingly, this straightening up also provides more elastic properties to the spine. In fact, the relative elastic bearing capacity of a stick in given by $n 2+1$, where $n$ is the number of curves. According to this law, the human spine is $(3 \times 3)+1$ more elastic than a straight stick. These alternating curves are located in the cervical, throracic and lumbar regions. The sacrum is not taken into account in this calculation as its vertebrae are fused. Maximal curvature points in Humans are C5, T7 and L3 (S3 being excluded).

Spine curvature appears progressively during evolution. Theriomorph Reptiles have a straight spine. In quadrupeds with parasagittal limbs such as Dogs and Horses, and even in Cynomorphs, the spine presents a single curvature, with a ventral concavity, located at the thoracolumbar junction, at the level of the 'limit' vertebra, which bears the last pair of real ribs (figure 10). This pattern is the fundamental curvature in Mammals. Semi-erected Mammals (Anthropomorphs) have a slight lumbar curvature in lordosis, increased in Humans, which also present cervical and sacral curvatures.

During Human ontogenesis, the curvature is at first global with a ventral concavity. The cervical curvature appears in children when they raise their head and the lumbar curvature is linked with gait.

Curvature modifies the ventral and dorsal heights of the vertebral bodies. According to Cunningham ${ }^{2}$, a vertebra is called coelorachic if its dorsal height exceeds its ventral height and cyrtorachic in the opposite case. When ventral and dorsal heights are equal, the vertebra is called orthorachic. These terms can also apply to a whole region of the spine. For instance, a lumbar lordosis is a cyrtorachia, that is an exagerated ventral convexity. Lordosis is most often found in caucasians, especially females, while black populations have a marked 


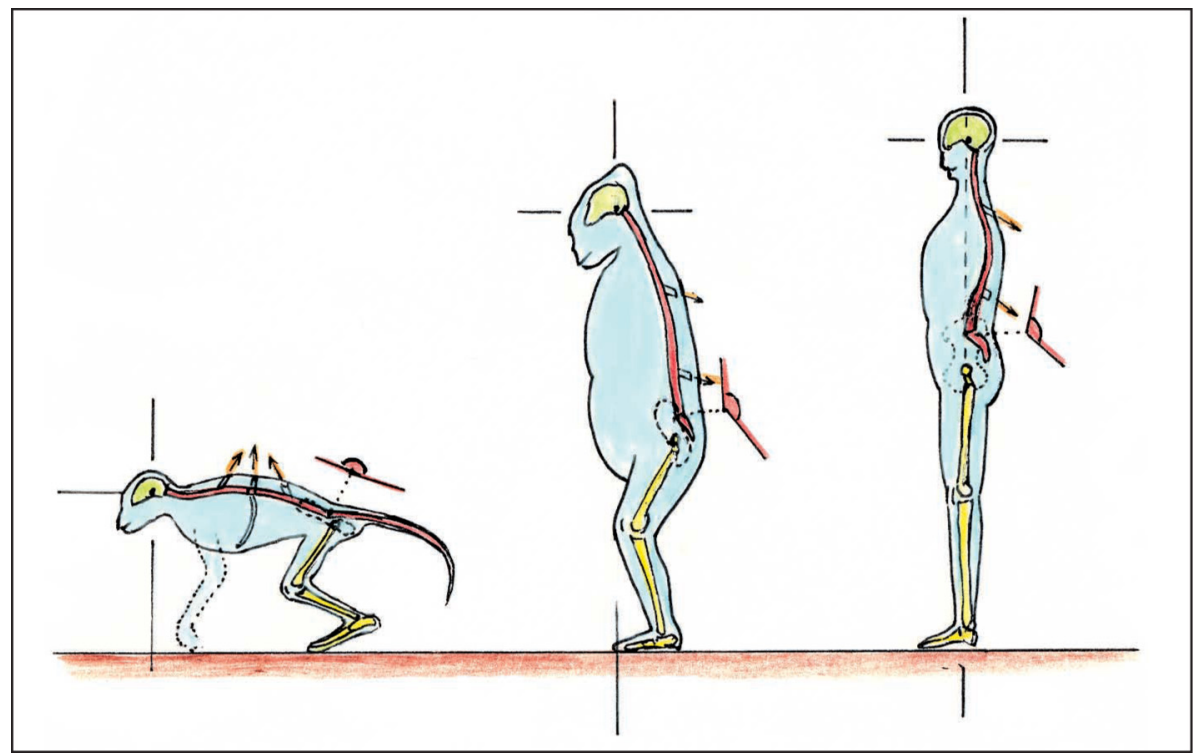

Figure 10

From left to right: cynomorph, anthropomorph, man; spine curvature, lumbo-sacral angles and processus spinosus directions; the vestibular axes of the head are drawn from the labyrinth, figured by a spot.

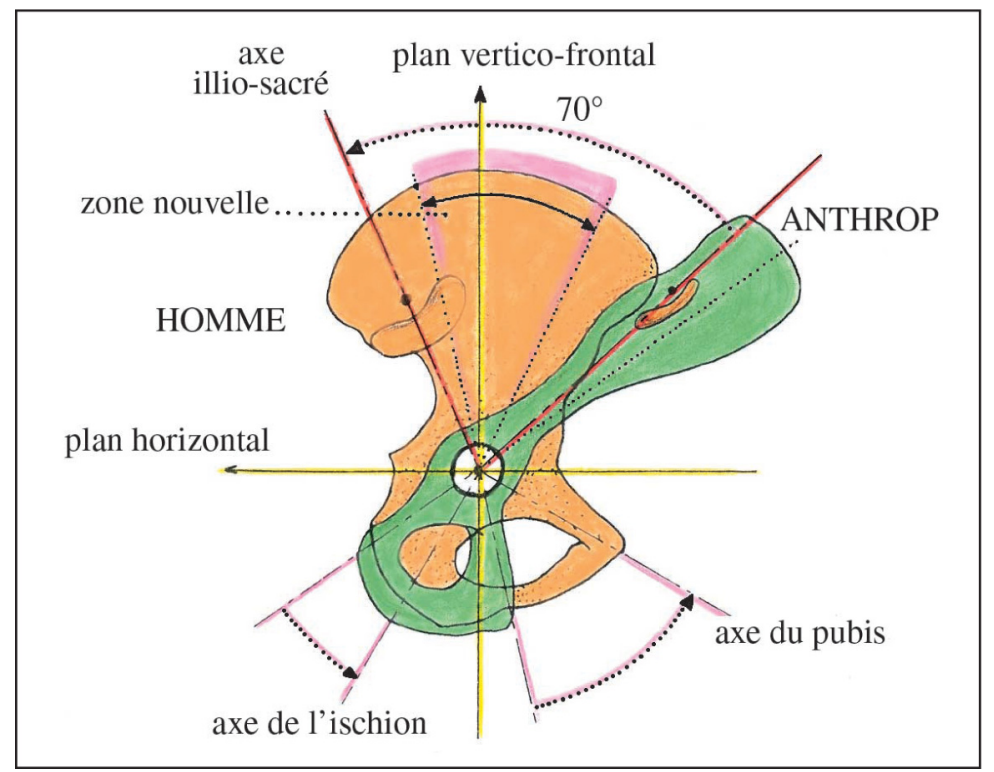

Figure 11

Rotatory evolution of the iliac bone components, from anthropomorphs to humans. 
tendency towards coelorachia. These conclusions have to be discussed according to the structure of the intervertebral discs.

The processus spinosus play a major role in standing position and locomotion. Their direction is orthogonal to the forces involved locally (figure 10). In a quadrupede (and even a Cynomorph), they are caudally oblique in the thoracic region ("retroclinia", or "synclinia"). The processus spinosus of the "limit" vertebra has a neutral mechanical role ("iso-clinia"). "Retroclinia" helps to support the cephalic extremity by the interplay of muscles and ligaments. "Anteclinia" is linked with the forces exerted in the lower limbs of quadrupeds. In Anthropomorphs and in Humans, lumbar anteclinia progressively leads to synclinia as sustaining the trunk requires more energy in standing position.

A mechanical model of the role of the processus spinosus was built by Thomson ${ }^{13}$, who compared their role to the "cantilevers" of the iron bridges. This "bridge theory" boasts that the spine is submitted to pressure (on vertebral bodies) and to tensions (via the ligaments and the thoracic muscles) transmitted by the processus spinosus. Another theory, the "bow theory", defended by Kummer and Slijper 8,12 , insists on the masses that exert their action the "bowed" structure formed by the spine, the ventral muscles being the string.

\section{- Spine, pelvic girdle and skull}

The fate of the pelvic girdle depends on the structure of the spine via the sacrum. From Cynomorphs to Humans, the iliac bone, influenced by the sacrum, modifies its form and its position. Its three subunits (ilion, ischion and pubis) follow the general rotation of the body axis with a slight inertia (figure 11).

The anterior (ventral) border of the iliac wing barely rotates while its dorsal portion, represented by the ilio-sacral axis, follows a $70^{\circ}$ amplitude movement, inducing the apparition of a fanshaped area, the gluteal area, where the gluteal muscles are inserted. These muscles are particularly developed in Humans and reduced in Primates. Buffon1 considered them even as a distinctive feature of the Human species! The ilio-sacral axis starts in the center of the cotyloïde cavity et

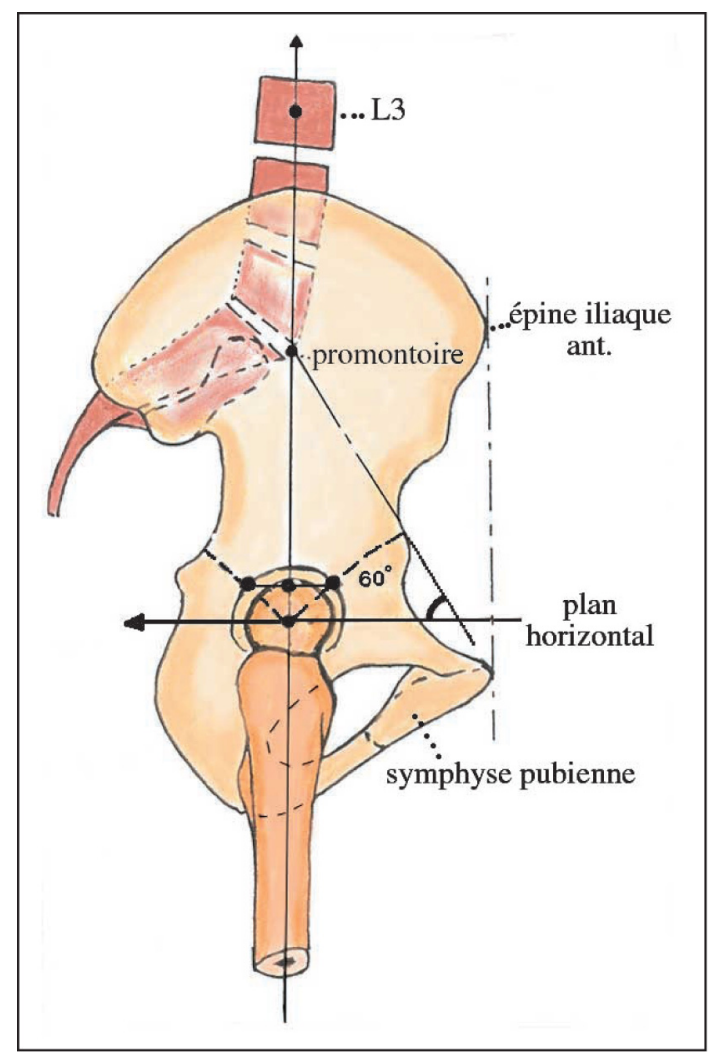

Figure 12

Human bassin orientation; are figures L3, the promontoire, the condyle center and the horizontal axe running through the condyle center. 
goes through the "nutation" center (limited movements between the sacrum and the iliac bones), located in the concavity of the articular surface.

The phylogenetic rotation of this axis has to be compared to the two other axes involving the ischion and the pubis. The amplitude of rotation of these two axes is smaller (resp. $20^{\circ}$ and $40^{\circ}$ ). The description of all these movements has to refer to standard frameworks. The vertical axis has already been defined (figure 10); in the pelvis, it is represented, in sagittal view, by (1) the centre of $L 3,(2)$ the promontory, (3) the "mesosinafeic" point (midpoint of the segment joining the points where the cotyloïdian border contacts the sutures between the ilion and two other subunits of the bone), and (4) the center of the femoral head cotyle.

The horizontal axis included this latter point and establishes a $60^{\circ}$ angle with the line joining the pubis to the promontory. The horizontal axis is perpendicular to the axis between the pubis and the anterior and superior iliac spine.

The acquisition of bipedia also involves modifications of the lower limbs and of the feet, but these tends will not be detailed in this paper.

The skull modifications must be briefly evoked. The amplitude of the transformations observed in the ilion parallels the changes noticed in the parieto-occipital region of the skull, with the same phylogenetic sequence. The question of the interdependence of these transformations has to be studied. Does brain volume augmentation induces an occipital pushback and a spine rotation? Or is the occipital rotation the consequence of the spinal straightening?

Conclusion. Spine phylogenesis cannot be studied independently and is linked to the development of other components of the body: the head, the pelvis and the limbs. A global consideration of the causes and the effects of this evolutionary history has to take this whole system into account.

Complements to this article available on

Travail du Laboratoire de Craniologie: 7, rue A. Delecourt, 59130 Lambersart.

\section{REFERENCES}

1. Buffon M. de. Histoire naturelle générale et particulière des animaux. Imprimerie royale. Paris: Panckouche éd, 1769.

2. Cunningham DJ. Reports of scientific results of exploring voyage of HMS challenger. Zool 1882;5, $192 \mathrm{p}$ et the significance of antomical variations. J Anat 1898:33.

3. Delmas A. L'acquisition de la station érigée. Coll. Sur les Processus d'hominisation. Paris: CNRS éd., 1958.

4. Gadow H. On the evolution of the vertebral column of Amphibia and Amniota. Phil Trans R Soc London 1896:187.

5. Gadow H. The evolution of the vertebral column. A contribution to the study of Vertebrate phylogeny. Cambridge Univ Press 1933:356.

6. Jarvik E. (trad. Lehman). Théories de l'évolution des Vertébrés reconsidérée a la lumière des récentes découvertes sur les Vertébrés inférieurs. Paris: Masson éd., 1960. 
7. Keith A. Man's posture, its evolution and disorders. Brit Med J 1923;1:451-689.

8. Kummer B. Funktioneller Bau und Funktionelle Anpassung des Knochen. Anat Anz 1962:111,261,293.

9. Pineau $H$, Delmas A. Poids du rachis et conditions d'écologie zoologique. Pr Méd 1960;6:68.

10. Pineau H, Delmas A. 1966.

11. Radlauer C. Beitrage zur Antropologie des kreuzbeiner. Morphol Jarhb 1908;38:323447. Poids des vertèbres et classification des Mammifères. Paris: C.R.Ac. des Sc., 262.

12. Slijper EJ. Comparative biologic anatomical investigations on the vertebral column and spinal musculature of Mammals. Verh Kon Ned Akad Wetens Afd Natuur Kunde 1946;5:42.

13. Thomson V d'Arcy. On growth and form. Cambridge: Univ. Press, 1917, 793 p.

14. Von Ebner V Urwirlbel und Neugliederung der Wirbelsäule. Wien: Sitzungsber d. K. Akad. D. Wiss. Bd. 1888:97.

\section{ADDITIONAL REFERENCES}

- Boué H, Chanton R. Zoologie. Paris: Doin éd., 1957.

- Dalcq A, Pasteels J. Une conception nouvelle des bases physiologiques de la morphogénèse. Arch. Biol 1937;48:669-710.

- Delattre A, Fenart R. L'hominisation du crane, étudiée par la méthode vestibulaire. Paris: C.N.R.S. éd., 1960.

- Devillers C. 1954. Structure et évolution de la colonne vertébrale. In: Grassé, Traité de Zoologie, XII. Paris: Masson éd., 605-72 \& 673-97.

- Fenart R. Influence des modifications expérimentales et tératologiques de la station et de la locomotion sur la morphologie céphalique des Mammifères quadrupèdes. Étude par la méthode vestibulaire. Th. Dr. es Sc. Nat., Lille, 1966.

- Fenart R. Ontogenèse craniologique vestibulaire. Analyse morphologique positionnelle. Lambersart: Éd. pers. (internent: www. Fraternet. Org/seret), 2006.

- Ledouble AF. Traité des variations de la colonne vertébrale chez l'Homme, et leur signification au point de vue de l'Anthropologie zoologique. Paris: Vigot éd., 1912:543.

- Lessertisseur J, Saban R. Squelette axial. In: Grassé, Traité de Zoologie, XVI. Paris: Masson éd., 1961:584-675.

- Merle P. La verticalité du corps humain. Biol. Méd. XLIX 1960:104.

- Olivier G. Anatomie anthropologique Paris: Vigot éd., 1965.

- Schultz A.H. Vertebral column and thorax. In: Hofer, Primatology 1960;5:4.

- Topinard P. Des anomalies de nombre de la colonne vertébrale de I'Homme. Rev. Anthrop 1877;6:577-649.

- Vallois HV. La sustentation de la tête et le ligament cervical postérieur chez l'Homme et les Anthropoides. L'Anthrop. 1926;36:191-207.

- Vialleton L. Éléments de Morphologie des Vertébrés. Paris: Doin éd., 1911. 